\title{
Simulasi Numerik Karakteristik Aliran Melintasi Dua Silinder Sirkular Tersusun Tandem Dekat Dinding Miring
}

\author{
Rida Arifah dan Wawan Aries Widodo \\ Departemen Teknik Mesin, Fakultas Teknologi Industri \\ Institut Teknologi Sepuluh Nopember (ITS) 60111 Indonesia \\ e-mail: buditem@me.its.ac.id
}

\begin{abstract}
Abstrak-Silinder sirkular yang berinteraksi dengan fluida adalah salah satu bentuk yang umum digunakan pada rekayasa teknik. Salah satu elemen struktural yang berbentuk silinder sirkular yaitu pipa. Instalasi perpipaan yang didirikan berkelompok atau dalam susunan tertentu sering ditemukan dalam bangunan industri. Salah satunya pada instalasi perpipaan di atas tanah untuk mengalirkan minyak dari sumur produksi menuju kilang minyak di daratan (Onshore) untuk diolah. Peletakan instalasi perpipaan di atas tanah pada umumnya diletakkan dengan jarak tertentu dari permukaan tanah, baik pada permukaan tanah yang datar atau dengan kemiringan tertentu. Penelitian ini menggunakan metode simulasi numerik dua dimensi steady dan incompressible flow menggunakan software CFD Ansys Fluent versi 19.1. Bilangan Reynolds yang digunakan dalam simulasi ini sebesar $5 \times 10^{4}$ dengan kecepatan inlet sebesar $20 \mathrm{~m} / \mathrm{s}$. Variasi yang dilakukan pada penelitian ini adalah rasio besar celah silinder sirkular dengan dinding $(\mathrm{G} / \mathrm{D})$ berturut-turut $0,1,0,2,0,3,0,4,0,5$, dan 1 , serta variasi kemiringan dinding $(\alpha)$ pada $0^{\circ}, 10^{\circ}$, dan $20^{\circ}$. Rasio jarak longitudinal antar dua silinder sirkular $(\mathrm{L} / \mathrm{D})=1,5$ dibuat konstan. Pemodelan turbulence viscous yang digunakan adalah shear stress transport $k-\omega$. Hasil yang didapat dari simulasi numerik secara kualitatif menunjukkan bahwa peningkatan (G/D) akan mengurangi pengaruh blockage dan peningkatan $(\alpha)$ akan membentuk wake akibat inclined wall serta meningkatkan pengaruh adverse pressure gradient. Hasil yang didapat secara kuantitatif yaitu peningkatan G/D dan $\alpha$ akan meningkatkan trendline CDp dan menurunkan trendline CLp pada silinder-1 serta menurunkan trendline $\mathrm{CDp}$ dan meningkatkan trendline CLp pada silinder-2. Tinjauan pada $\alpha$ dapat disimpulkan bahwa peningkatan $\alpha$ pada setiap G/D akan menurunkan nilai CDp dan CLp pada silinder-1 serta meningkatkan CDp (tetap bernilai negatif) dan menurunkan CLp pada silinder-2. Dapat disimpulkan bahwa jarak (L/D) $=1,5$ menyebabkan gaya drag yang semakin rendah pada silinder-2, disebabkan oleh free shear layer silinder-1 melingkupi silinder-2 pada $\alpha=0^{\circ}$ dan $10^{\circ}$. Pada $\alpha=20^{\circ}$ pengurangan gaya drag silinder-2 diakibatan oleh wake step dari inclined wall.
\end{abstract}

Kata Kunci-Silinder Sirkular, Susunan Tandem, Dinding Miring, Drag dan Lift Coefficient, Wake Step.

\section{PENDAHULUAN}

$\mathrm{I}_{\mathrm{b}}^{\mathrm{N}}$ NDONESIA memiliki potensi sumber daya alam yang Lesar, salah satunya yaitu minyak bumi dan gas alam. Sumber daya alam perlu diolah menjadi suatu produk agar dapat menunjang kesejahteraan kehidupan masyarakat. Salah satunya dibutuhkan Instalasi perpipaan di atas tanah untuk mengalirkan minyak dari sumur produksi menuju kilang minyak di daratan (Onshore) untuk diolah. Peletakan instalasi perpipaan di atas tanah pada umumnya diletakkan dengan jarak tertentu dari permukaan tanah, baik pada permukaan tanah yang datar atau dengan kemiringan tertentu. Peletakan instalasi perpipaan memberikan pengaruh yang signifikan terhadap karakteristik aliran udara yang melintasinya. Karakteristik aliran tersebut berupa fenomena aliran yang nantinya akan menimbulkan gaya angkat dan gaya tahan pada instalasi perpipaan.

Karakteristik aliran tersebut telah diteliti oleh [1] dengan melakukan eksperimen pada silinder sirkular tunggal yang diletakkan dekat dinding dengan menggunakan wind tunnel. Bilangan Reynolds yang digunakan dalam eksperimen ini adalah $2,5 \times 10^{4}$ dan $4,8 \times 10^{4}$ yang didasarkan pada diameter silinder. Variasi eksperimen dilakukan pada besar celah antara silinder sirkular dengan dinding sebesar $\mathrm{G} / \mathrm{D}=0$ hingga $G / D=3,5$. Hasil yang didapatkan dari eksperimen ini menunjukkan bahwa fenomena vortex shedding pada silinder sirkular terjadi dengan bilangan Strouhal yang konstan untuk $\mathrm{G} / \mathrm{D} \geq 0,3$. Vortex shedding yang terjadi akan teredam apabila silinder sirkular didekatkan dengan dinding $(\mathrm{G} / \mathrm{D}<0,3)$. Vortex shedding adalah fenomena aliran yang berosilasi sehingga menghasilkan gaya lift yang berfluktuasi pada silinder sirkular. Gaya lift yang berfluktuasi tersebut memberikan beban dinamis pada silinder sirkular, sehingga peluang kegagalan struktur menjadi semakin besar. Hasil selanjutnya yaitu peningkatan G/D akan menghasilkan distribusi tekanan yang lebih simetris. Distribusi tekanan hampir simetris sempurna saat $\mathrm{G} / \mathrm{D}=0,4$. Pada $\mathrm{G} / \mathrm{D}$ yang rendah titik separasi di sisi bawah silinder sirkular bergeser menuju trailing edge (sudut $180^{\circ}$ pada silinder sirkular) akibat adanya favorable pressure gradien.

Penelitian secara numerik mengenai aliran melintasi dua silinder sirkular disusun tandem dekat dinding datar telah dilakukan oleh [2]. Data eksperimen yang digunakan sebagai pembanding dari hasil simulasi adalah data hasil eksperimen oleh [3]. Kedua penelitian ini dilakukan pada Bilangan

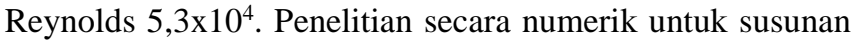
tandem dengan variasi rasio jarak longitudinal kedua silinder (L/D) dari 1,5; 2; 3; 4; 5; 6. Rasio besar celah silinder sirkular ke dinding dijaga konstan yaitu pada $\mathrm{G} / \mathrm{D}=0,2$. Sedangkan penelitian dengan eksperimen dilakukan pada L/D konstan yaitu 1,5 dengan variasi G/D mulai 0 hingga 0,467 . Hasil yang didapat dari simulasi numerik yaitu bahwa variasi (L/D) yang semakin meningkat memberikan pengaruh berkurangnya interaksi antara ke dua silinder sirkular. Namun keberadaan dinding tetap memberikan pola aliran masingmasing pada silinder sirkular. Akibat adanya dinding berpengaruh pada pressure recovery pada dinding hingga $\mathrm{x} / \mathrm{D}$ $>$ 12. Pada jarak L/D $<4$ akan mengurangi koefisien drag akibat tekanan pada silinder-2 karena free shear layer silinder-1 melingkupi silinder-2. Dengan hasil yang sama dari 
eksperimen didapat bahwa distribusi tekanan kedua silinder sirkular dipengaruhi oleh keberadaan dinding datar.

Penelitian mengenai kemiringan dinding diteliti secara simulasi numerik oleh [4] dalam 2D dan 3D aliran turbulen inkompresibel pada backward facing inclined step. Variasi sudut yang digunakan sebesar $10^{\circ}, 25^{\circ}, 45^{\circ}$ dan $90^{\circ}$. Hasil simulasi numerik tersebut dibandingkan dengan penelitian secara eksperimen oleh [5]. Hasil kedua penelitian tersebut yaitu pada kemiringan step yang semakin besar akan menghasilkan panjang reattachment yang semakin besar sehingga terbentuk recirculation zone yang juga semakin besar.

Berdasarkan studi pustaka tersebut diatas, maka penelitian ini bertujuan untuk menganalisis karakteristik aliran yang melintasi dua silinder sirkular yang tersusun tandem dekat dinding miring menggunakan simulasi numerik. Variasi yang dilakukan adalah rasio besar celah dinding dengan silinder sirkular terhadap diameter $(\mathrm{G} / \mathrm{D})=0,1,0,2,0,3,0,4,0,5,1$ dan variasi kemiringan dinding pada sudut $0^{\circ}, 10^{\circ}$, dan $20^{\circ}$. Rasio jarak longitudinal antar dua silinder sirkular terhadap diameter $(\mathrm{L} / \mathrm{D})=1,5$ dibuat konstan. Selain karakteristik aliran, tujuan dari tugas akhir ini adalah menganalisis distribusi dari koefisien tekanan $\left(\mathrm{C}_{\mathrm{p}}\right)$ kedua silinder sirkular dan dinding, dan nilai koefisien pressure drag (CDp) serta koefisien pressure lift (CLp) pada kedua silinder sirkular yang tersusun tandem dekat dinding miring.

\section{URAIAN PENELITIAN}

Pembuatan domain simulasi untuk menganalisis karakteristik aliran fluida pada dua silinder sirkular tandem dekat dinding miring dilakukan seperti pada Gambar 1.

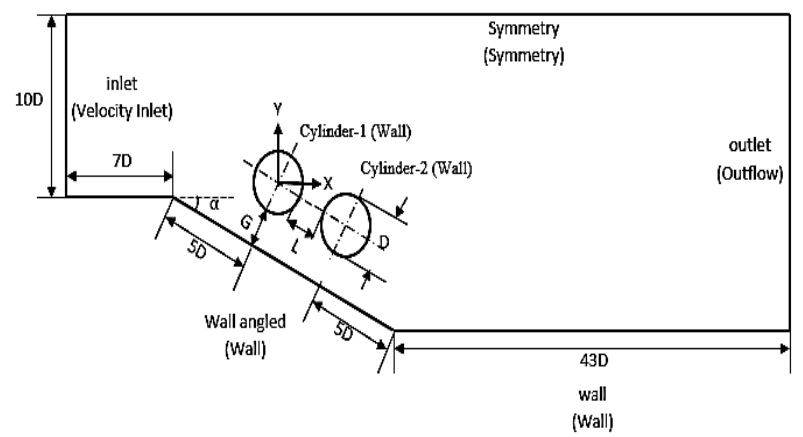

Gambar 1. Domain simulasi dan boundary condition aliran melintasi dua silinder sirkular dekat dinding miring

Domain simulasi terdiri dari dua silinder sirkular yang disusun tandem dengan diameter sebesar D dan jarak pusat ke pusat kedua silinder sirkular sebesar (L). Kedua silinder sirkular tersebut diletakkan dekat dinding dengan jarak celah sebesar (G) dan kemiringan dinding sebesar $(\alpha)$ terhadap bidang horizontal. Pada domain tersebut dilakukan variasi besar celah $(G)$ dan kemiringan dinding $(\alpha)$. Nilai variabel geometri diatas menggunakan skala diameter silinder yaitu $\mathrm{D}$ $=40 \mathrm{~mm}$.

Selanjutnya dilakukan proses meshing seperti pada Gambar 2. Meshing merupakan tahap pembagian sebuah domain simulasi menjadi volume yang lebih kecil yang disebut sebagai elemen. Meshing berfungsi sebagai control volume pada domain simulasi yang akan diselesaikan oleh software ANSYS Fluent 19.0. Meshing dengan kualitas baik dapat menghasilkan data yang akurat. Bentuk meshing yang digunakan yaitu quadrilateral structured 2-D mesh.

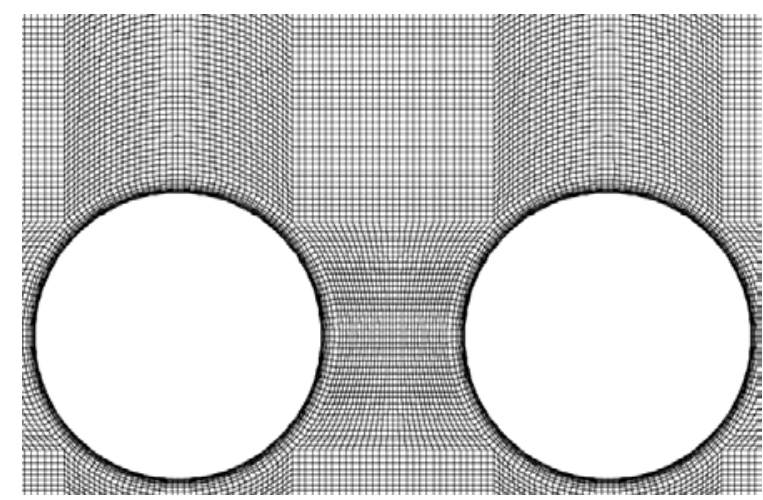

Gambar 2. Meshing dari domain simulasi

Pemodelan fenomena fisis yang digunakan yaitu pressurebased solver, steady flow, dan shear stress transport k- $\omega$ turbulence modeling. Pemodelan turbulen shear stress transport $k-\omega$ turbulence modeling dipilih berdasarkan literatur [6] yang menyatakan bahwa pemodelan turbulensi shear stress transport k- $\omega$ memberikan performa yang terbaik untuk kasus simulasi pada kasus aliran eksternal dan memiliki performa baik dalam menganalisis aliran yang dekat dengan dinding.

Fluida kerja yang digunakan dalam simulasi numerik yaitu udara dengan temperatur $300 \mathrm{~K}$ pada tekanan atmosfer. Properti udara didapatkan dari literatur [7] dengan nilai densitas fluida $(\rho)$ dan viskositas absolut $(\mu)$. Nilai yang diinput pada boundary condition yaitu velocity inlet, intensitas turbulensi, dan length scale. Bilangan Reynolds yang digunakan pada penelitian ini didasarkan pada data eksperimental [8] yang melakukan pengukuran tekanan pada $\mathrm{Re}=5 \times 10^{4}$. Dari Bilangan Reynolds tersebut, didapat nilai velocity inlet sebesar $20 \mathrm{~m} / \mathrm{s}$. Intensitas turbulensi yang digunakan berdasarkan eksperimen [8] sebesar 0,1\% dan length scale sebesar $0,0044 \mathrm{~m}$. Nilai length scale didapatkan dari persamaan (1) yaitu:

$$
l=0,4 \delta_{99}=0,4\left(\frac{0,382 R e^{4 / 5} \mu}{\rho V}\right)
$$

Dengan mengasumsikan bahwa aliran pada inlet telah melintasi plat datar dan berada pada kondisi tepat transisi menuju turbulen. Persamaan diatas didapatkan dari [8].

Grid independency test dilakukan untuk mengetahui pengaruh kualitas meshing terhadap hasil data simulasi numerik yang didapatkan dengan cara membandingkan kerapatan meshing. Perbandingan dilakukan mulai dari kerapatan mesh yang renggang (coarse), menengah (medium), rapat (fine), dan sangat rapat (very fine). Nilai yang dibandingkan pada grid independency test adalah nilai CDp silinder-1. Tabel 1 menunjukkan perbandingan CDp tiap tingkat kerapatan mesh. nilai CDp tidak berubah signifikan pada tingkat kerapatan mesh 344744 dan 451106 nodes. Kesimpulan perubahan nilai yang tidak signifikan tersebut turut didukung oleh kesalahan relatif yang cukup rendah yaitu 0,4424\%. Berdasarkan pengamatan tersebut, maka tingkat kerapatan mesh yang digunakan pada tugas akhir ini adalah kerapatan mesh C dengan jumlah nodes 344744.

Tabel 1.

Perbandingan CDp silinder-1 pada setiap tipe mesh

\begin{tabular}{ccccc}
\hline \hline Tipe Mesh & $\mathbf{y}^{+}$ & Jumlah Nodes & CDp & Relative Error (\%) \\
\hline A & 1.5 & 147976 & 0.9559 & - \\
B & 1.3 & 245234 & 0.9675 & 1.1989 \\
C & 1 & 344744 & 0.9718 & 0.4424 \\
D & 0.5 & 451106 & 0.9719 & 0.0102 \\
\hline \hline
\end{tabular}




\section{A. Persamaan-persamaan yang Digunakan}

Persamaan-persamaan yang digunakan pada penelitian ini adalah Bilangan Reynolds, Koefisien Tekanan, Koefisien Drag dan Lift akibat Tekanan, dan Integrasi Komposit Simpson's Rule.

Bilangan Reynolds terdiri dari densitas $\rho$, kecepatan freestream $\mathrm{V}_{\infty}$, diameter silinder sirkular $\mathrm{D}$, dan viskositas absolut $\mu$.

$$
R e=\frac{\rho V_{\infty} D}{\mu}
$$

Koefisien tekanan merupakan rasio antara gaya tekanan yang terjadi pada suatu bodi dengan gaya inersia fluida. Koefisien tekanan terdiri dari tekanan kontur p, tekanan freestream $\mathrm{p}_{\infty}$, densitas $\rho$, dan kecepatan freestream $\mathrm{V}_{\infty}$

$$
C_{\boldsymbol{p}}=\frac{p-p_{\infty}}{\frac{1}{2} \rho V_{\infty}^{2}}
$$

Koefisien drag akibat tekanan merupakan integrasi dari koefisien tekanan. Koefisien ini menunjukkan gaya drag pada bodi yang dihasilkan dari tekanan. Koefisien ini terdiri dari Cp kontur dan sudut posisi kontur $\theta$. Gaya drag memiliki arah sejajar dengan sumbu x pada Gambar 3.

$$
C_{D p}=\frac{1}{2} \int_{0}^{2 \pi} C_{p} \cos \theta d \theta
$$

Koefisien lift akibat tekanan merupakan integrasi dari koefisien tekanan. Koefisien ini menunjukkan gaya lift pada bodi yang dihasilkan dari tekanan. Koefisien ini terdiri dari Cp kontur dan sudut posisi kontur $\theta$. Gaya lift memiliki arah sejajar dengan sumbu y pada Gambar 3.

$$
C_{L p}=-\frac{1}{2} \int_{0}^{2 \pi} C_{p} \sin \theta d \theta
$$

Evaluasi nilai integral dari koefisien drag dan lift didapatkan dengan menggunakan integrasi komposit Simpson's Rule. Rumus Simpson's Rule terdiri dari batas atas data b, batas bawah data a, jumlah data n, data ke i xi, index i dan $\mathrm{j}$ :

$$
\int_{a}^{b} f(x) d x \approx \frac{b-a}{3 n}\left[f\left(x_{0}\right)+4 \sum_{i=1}^{i=1,3,5, \ldots} f\left(x_{i}\right)+2 \sum_{j=2}^{j=2,4,6, \ldots} f\left(x_{j}\right)+f\left(x_{n}\right)\right]
$$

Persamaan (2) hingga (5) diatas mengacu pada Gambar 3 berikut:
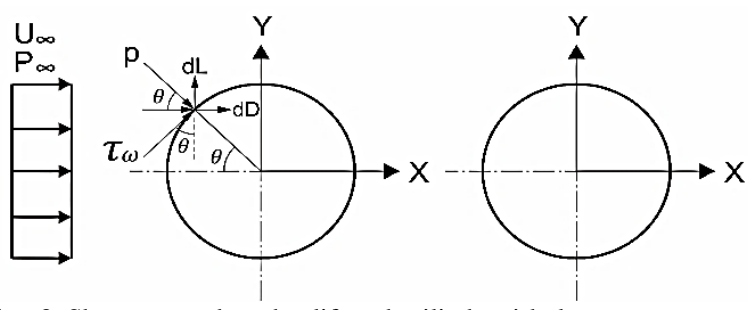

Gambar 3. Skema gaya drag dan lift pada silinder sirkular

\section{HASIL SIMULASI NUMERIK}

Pembahasan yang akan dianalisis berupa karakteristik aliran dengan pengaruh variasi (G/D) pada setiap variasi $(\alpha)$, koefisien drag dan lift akibat tekanan pada silinder-1 serta visualisasi aliran setiap variasi $(\alpha)$ pada $G / D=0,2$ (konstan).

\section{A. Pengaruh G/D Terhadap Karakteristik Aliran pada Variasi $\alpha=0^{\circ}$}

Pengamatan distribusi tekanan silinder-1 pada Gambar 4 menunjukkan bahwa distribusi Cp upper side silinder-1 pada dengan $\mathrm{G} / \mathrm{D}=$ 0,1 memiliki Cp maksimum lebih rendah dari G/D lainnya. Ketika G/D ditingkatkan, titik stagnasi secara bertahap berangsur naik mendekati $\mathrm{Cp}=1$. Pengamatan pada distribusi Cp upper side silinder-1, menunjukkan Cp minimum $\mathrm{G} / \mathrm{D}=0,1$ memiliki nilai yang lebih rendah dari G/D lainnya. Hal ini menunjukkan bahwa pada $\mathrm{G} / \mathrm{D}=0,1$ aliran mengalami akselerasi di sisi atas silinder lebih tinggi dibandingkan G/D lainnya.

Pengamatan pada distribusi Cp lower side silinder-1, Cp minimum menunjukkan bahwa $\mathrm{G} / \mathrm{D}=0,1$ mengalami akselerasi yang lebih rendah secara signifikan pada sisi bawah-depan $\left(270^{\circ}<\theta<360^{\circ}\right)$ dibandingkan G/D lainnya. Peningkatan $\mathrm{G} / \mathrm{D}$ akan meningkatkan akselerasi aliran pada sisi bawah-depan silinder-1 $\left(270^{\circ}<\theta<360^{\circ}\right)$ dan menggeser Cp minimum menuju leading edge.

Keberadaan silinder-2 memberikan pengaruh terhadap blockage pada sisi celah antar kedua silinder. Hal tersebut terlihat dimana blockage tersebut menimbulkan adanya forward shear layer yang ditandai dengan adanya peak pada kisaran $\left(170^{\circ}<\theta<190^{\circ}\right)$. Pengamatan pada keseluruhan grafik Cp silinder-1 menunjukkan bahwa penurunan tekanan pada lower side silinder lebih besar dari pada penurunan tekanan pada upper side. Hal ini mengindikasikan bahwa akselerasi di sisi celah antara silinder dengan lower wall lebih besar dari pada akselarasi di upper side silinder sirkular. Hal ini diakibatkan oleh luas penampang di bagian bawah silinder sirkular lebih kecil dibandingkan dengan luas penampang pada sisi atas silinder sirkular.

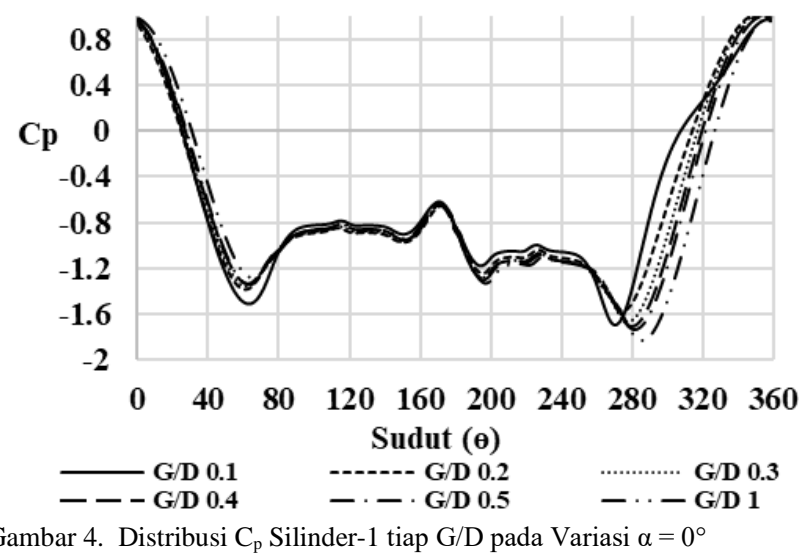

Gambar 5 merupakan grafik distribusi tekanan silinder-2. Pengamatan pada keseluruhan variasi G/D menunjukkan bahwa Cp upper side silinder-2 seluruhnya berharga negatif. Hal ini menunjukkan bahwa free-shear layer silinder-1 melingkupi silinder-2. Pengamatan pada distribusi Cp lower side silinder-2 pada keseluruhan variasi G/D kisaran sudut $300^{\circ}<\theta<330^{\circ}$, menunjukkan adanya puncak (peak). Hal ini menjelaskan adanya fenomena reattachment yaitu pelekatan kembali free shear layer bawah silinder-1 pada silinder-2 bagian bawah. Dimana pada posisi tersebut aliran fluida pada sisi celah terbagi dalam forward shear layer yang menuju silinder-1 dan backward shear layer yang bergerak ke dalam celah silinder sirkular-2. Peningkatan G/D menyebabkan puncak reattachment semakin naik. Pada lower side silinder2, yaitu pada Cp minimum akan menurun ketika G/D ditingkatkan hingga $G / D=0,3$. Namun peningkatan $G / D$ lebih lanjut akan meningkatkan nilai Cp minimum. Hal ini mengindikasikan bahwa $\mathrm{G} / \mathrm{D}=$ 0,3 merupakan jarak optimum antara silinder dengan lower wall.

\section{B. Pengaruh G/D Terhadap Karakteristik Aliran pada Variasi $\alpha=10^{\circ}$}

Pengamatan distribusi tekanan silinder-1 pada Gambar 6 menunjukkan bahwa $\mathrm{Cp}$ maksimum pada $\mathrm{G} / \mathrm{D}=0,1$ upper side dan lower side lebih rendah dari dari G/D lainnya. Cp maksimum tersebut meningkat dan bergeser menuju leading 
edge $\left(\theta=0^{\circ}\right)$ saat G/D ditingkatkan. Pengamatan pada Cp minimum menunjukkan bahwa $\mathrm{Cp}$ minimum pada $\mathrm{G} / \mathrm{D}=0,1$ lebih besar dari G/D lainnya. Apabila G/D ditingkatkan maka Cp minimum akan menurun. Hal ini mengindikasikan akselerasi yang semakin besar pada upper side $\left(60^{\circ}<\theta<80^{\circ}\right)$ ketika G/D ditingkatkan karena adanya pengaruh dari kemiringan dinding.

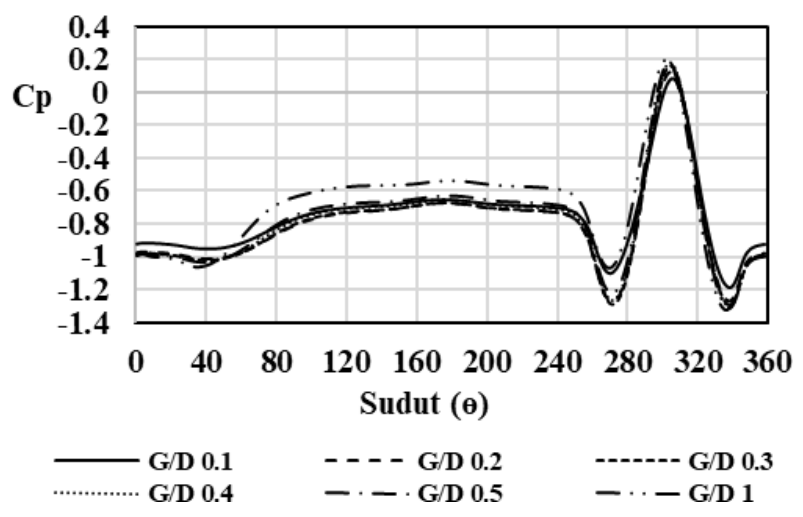

Gambar 5. Distribusi Cp Silinder-2 tiap G/D pada Variasi $\alpha=0^{\circ}$

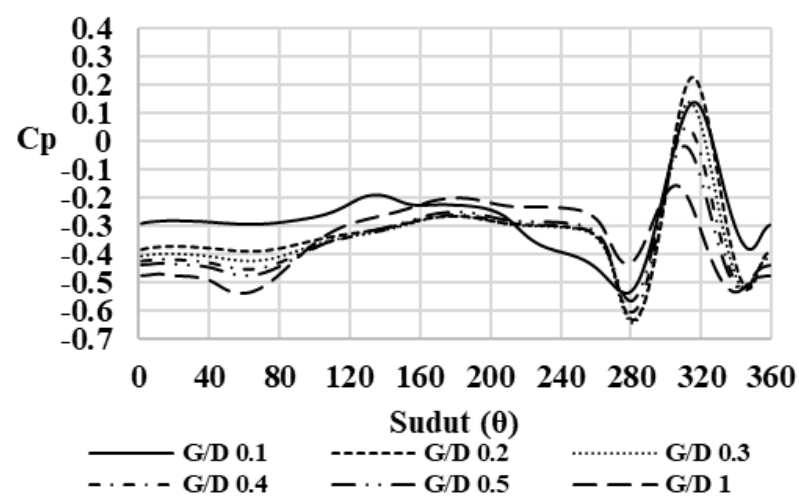

Gambar 7. Distribusi Cp Silinder-2 tiap G/D pada Variasi $\alpha=10^{\circ}$

\section{Pengaruh G/D Terhadap Karakteristik Aliran pada Variasi $\alpha=20^{\circ}$}

Pengamatan distribusi tekanan silinder-1 pada Gambar 8 menunjukkan bahwa nilai $\mathrm{Cp}$ pada $\mathrm{G} / \mathrm{D} \leq 0,4$ mendekati nol. Hal ini menunjukan bahwa nilai tekanan wall silinder-1 mendekati sama dengan tekanan statis karena seilinder-1 sepenuhnya berada dalam recirculation zone akibat wake step dari kemiringan dinding.

C. Pengaruh G/D Terhadap Karakteristik Aliran pada Variasl $\alpha=10^{\circ}$

Pengamatan distribusi tekanan silinder-1 pada Gambar 6 menunjukkan bahwa $\mathrm{Cp}$ maksimum pada $\mathrm{G} / \mathrm{D}=0,1$ upper side dan lower side lebih rendah dari dari G/D lainnya. Cp maksimum tersebut meningkat dan bergeser menuju leading edge $\left(\theta=0^{\circ}\right)$ saat G/D ditingkatkan. Pengamatan pada Cp minimum menunjukkan bahwa Cp minimum pada G/D = 0,1 lebih besar dari G/D lainnya. Apabila G/D ditingkatkan maka Cp minimum akan menurun. Hal ini mengindikasikan akselerasi yang semakin besar pada upper side $\left(60^{\circ}<\theta<80^{\circ}\right)$ ketika G/D ditingkatkan karena adanya pengaruh dari kemiringan dinding.

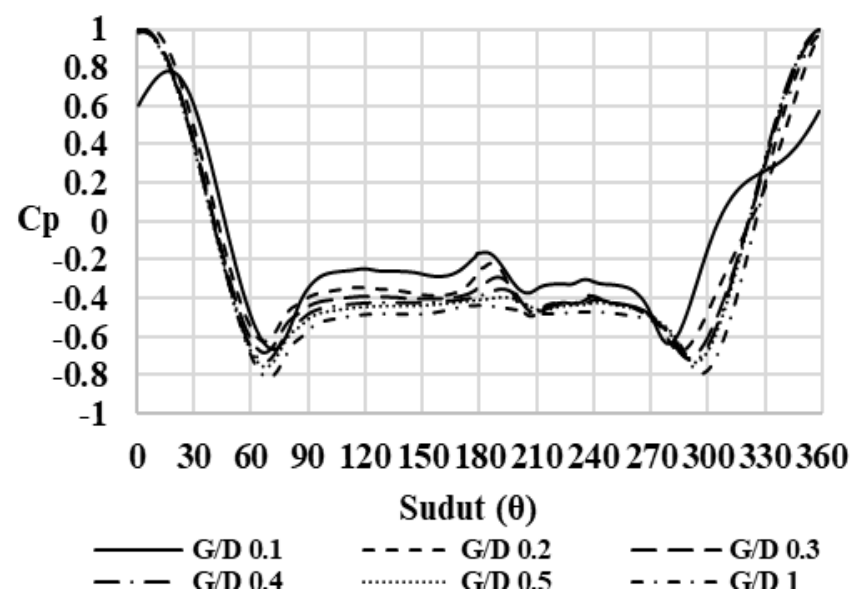

Gambar 6. Distribusi Cp Silinder-1 tiap G/D pada Variasi $\alpha=10^{\circ}$

Gambar 7 menunjukan grafik distribusi tekanan silinder-2. Pengamatan pada upper side silinder menunjukan bahwa pada seluruh variasi G/D Cp bernilai negatif. Hal ini disebabkan oleh adanya free shear layer silinder-1 yang melingkupi silinder-2. Pengamatan pada lower side silinder2 menunjukan adanya peak yang mengindikasikan adanya reattachment pada kisaran $\left(310^{\circ}<\theta<320^{\circ}\right)$. Pengamatan lebih detail pada puncak reattachment menunjukan bahwa peningkatan G/D akan menurunkan puncak reattachment. Pada lower side silinder-2, yaitu pada Cp minimum akan menurun ketika G/D ditingkatkan hingga $G / D=0,3$. Namun peningkatan G/D lebih lanjut akan meningkatkan nilai $\mathrm{Cp}$ minimum. Hal ini mengindikasikan bahwa $\mathrm{G} / \mathrm{D}=0,3$ merupakan jarak optimum antara silinder ke lower wall.

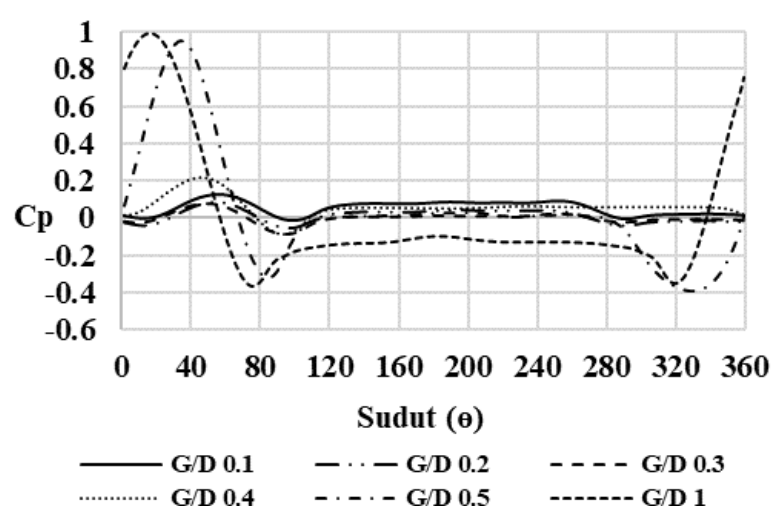

Gambar 8. Distribusi Cp Silinder-1 tiap G/D pada Variasi $\alpha=20^{\circ}$

Peningkatan G/D, menyebabkan fluktuasi grafik distribusi Cp. Hal ini menjelaskan bahwa semakin besar G/D divariasikan, pengaruh keberadaan lower wall semakin kecil sehingga silinder sirkular keluar dari lingkup recirculation zone. Pada G/D = 0,5 dan 1 kedua silinder sirkular telah keluar dari daerah resirkulasi, ditunjukan dengan adanya Cp maksimum. Cp maksimum pada upper side silinder-1 menunjukkan bahwa peningkatan G/D dari 0,5 menuju 1 akan meningkatkan Cp maksimum.

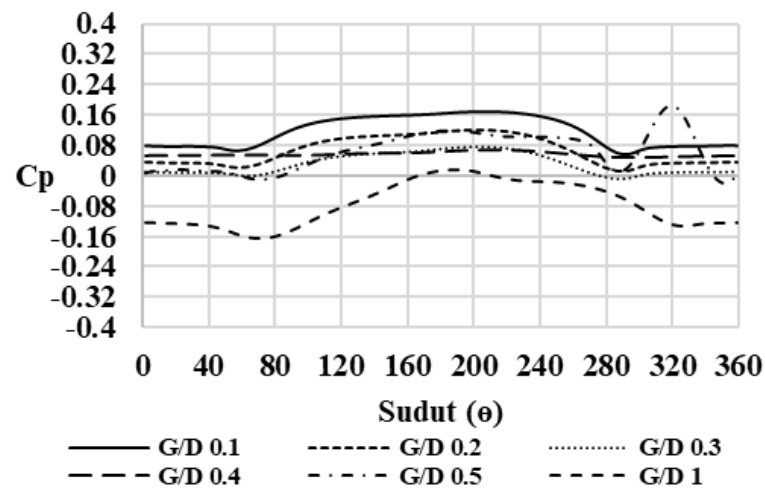

Pengamatan pada Gambar 9 distribusi Cp upper side dan lower side silinder-2, menunjukan bahwa nilai Cp pada G/D $\leq 0,4$ mendekati nol. Hal ini menunjukkan bahwa tekanan wall silinder-2 mendekati sama dengan tekanan statis. Mengindikasikan bahwa pada $\mathrm{G} / \mathrm{D}=0,1$ hingga 0,4 silinder-
Gambar 9. Distribusi Cp Silinder-1 tiap G/D pada Variasi $\alpha=20^{\circ}$ 
2 sepenuhnya terlingkup dalam recirculation zone akibat wake step dari kemiringan dinding.

Pengamatan pada $\mathrm{G} / \mathrm{D}=0,5$ menunjukkan bahwa pada lower side silinder- 2 terbentuk peak pada $\left(310^{\circ}<\theta<325^{\circ}\right)$. Hal ini mengindikasikan adanya reattachment dari free shear layer yang terseparasi pada lower side silinder-1.

\section{E. Koefisien Drag dan Lift Tekanan}

Analisis pengaruh jarak celah (G/D) dan inclined wall angle $(\alpha)$ pada karakteristik aliran dilakukan dengan pengolahan data CDp dan CLp dari integrasi persamaan (6). Gambar 10 menunjukkan nilai CDp silinder-1, bahwa semakin besar $\alpha$ dan G/D, trendline nilai CDp silinder-1 akan mengalami peningkatan. Peninjauan berdasarkan variasi $\alpha$ pada setiap G/D menunjukkan bahwa peningkatan $\alpha$ menyebabkan penurunan nilai CDp silinder-1. Hal ini mengindikasikan bahwa peningkatan kemiringan dinding menyebabkan wake blockage semakin besar, sehingga mengurangi distribusi tekanan di bawah depan silinder-1 sehingga CDp juga akan menurun.

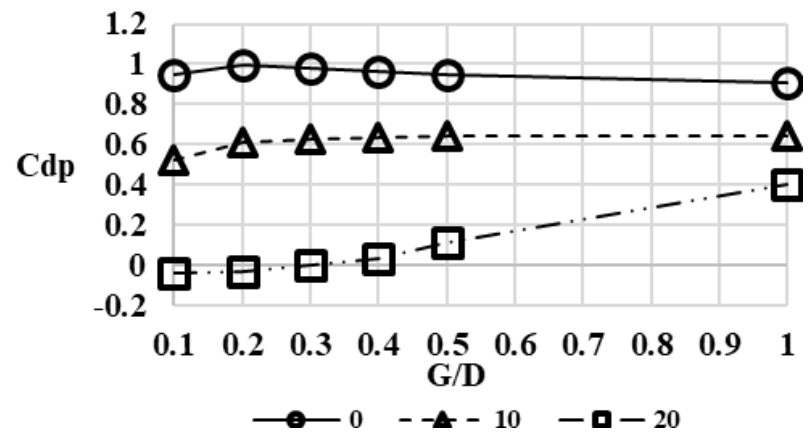

Gambar 10. Nilai $C_{D p}$ silinder-1 tiap $\mathrm{G} / \mathrm{D}$ pada berbagai variasi $\alpha$

Pembahasan nilai CLp silinder-1 pada Gambar 11 menunjukkan bahwa semakin besar G/D dan $\alpha$ maka trendline CLp silinder-1 mengalami penurunan. Peninjauan berdasarkan variasi $\alpha$ pada setiap G/D, menunjukkan bahwa peningkatan $\alpha$ menyebabkan penurunan nilai CLp silinder-1. Pengamatan pada kemiringan dinding, menyebabkan penurunan nilai CLp yang berharga negatif atau downforce. nilai CLp positif hanya ditunjukkan pada $\mathrm{G} / \mathrm{D}=0,1$ dan 0,2 pada tanpa kemiringan dinding. CLp negatif menunjukkan bahwa distribusi tekanan pada upper side silinder lebih besar dari pada distribusi tekanan pada lower side sehingga menyebabkan gaya tekan ke bawah menuju lower wall.

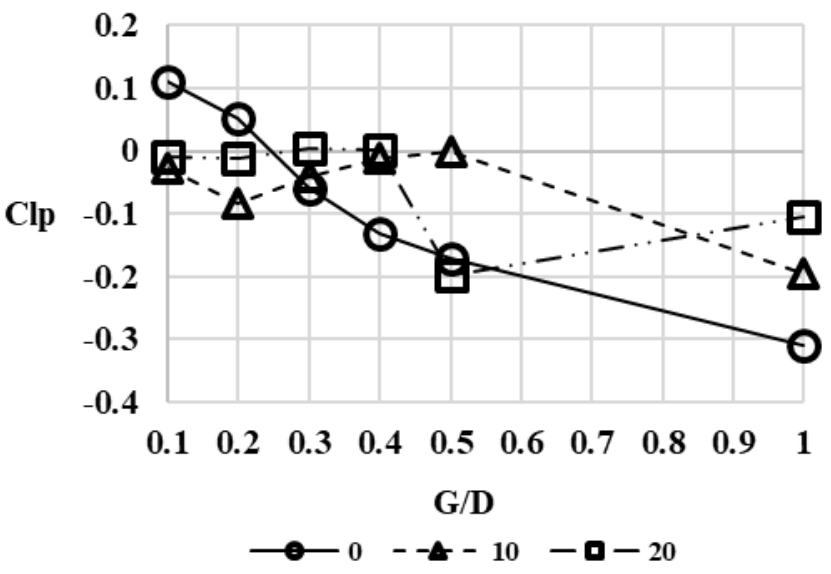

Gambar 11. Nilai $C_{L p}$ silinder-1 tiap G/D pada berbagai variasi $\alpha$

Perilaku dari CDp dan CLp pada $\alpha=10^{\circ}$ dan $20^{\circ}$ dipengaruhi oleh fenomena blockage dan adverse pressure gradient. Adverse pressure gradient mengurangi momentum aliran upstream, sehingga aliran akan cenderung membentuk wake yang lebih besar. Pada G/D = 0,2 pengaruh blockage berkurang dan meningkatkan laju massa aliran sisi bawah, sehingga menghasilkan momentum aliran yang cukup besar untuk melawan pengaruh aliran sekunder. Akselerasi yang besar di sisi bawah akan menurunkan tekanan dan CLp juga menurun. Blockage yang berkurang menyebabkan kenaikan tekanan pada sisis bawah-depan silinder-1 sehingga meningkatkan CDp.

Visualisasi aliran pada Gambar 12 menjadi pendukung data kuantitatif pada pembahasan diatas. Visualisasi dengan $\mathrm{G} / \mathrm{D}=0,2$ menunjukkan bahwa peningkatan $\alpha$ akan memperbesar blockage di sisi depan bawah silinder- 1 pada $\alpha$ $=10^{\circ}$. Namun akan membentuk wake step pada $\alpha=20^{\circ}$ sehingga dengan jarak celah yang kecil antara silinder dengan lower wall, kedua silinder sirkular akan terendam dalam recirculation zone. Recirculation zone merupakan daerah arus balik aliran yang ditandai dengan arah kecepatan yang berlawanan dengan kecepatan masuk (ke arah sumbu-x negatif).
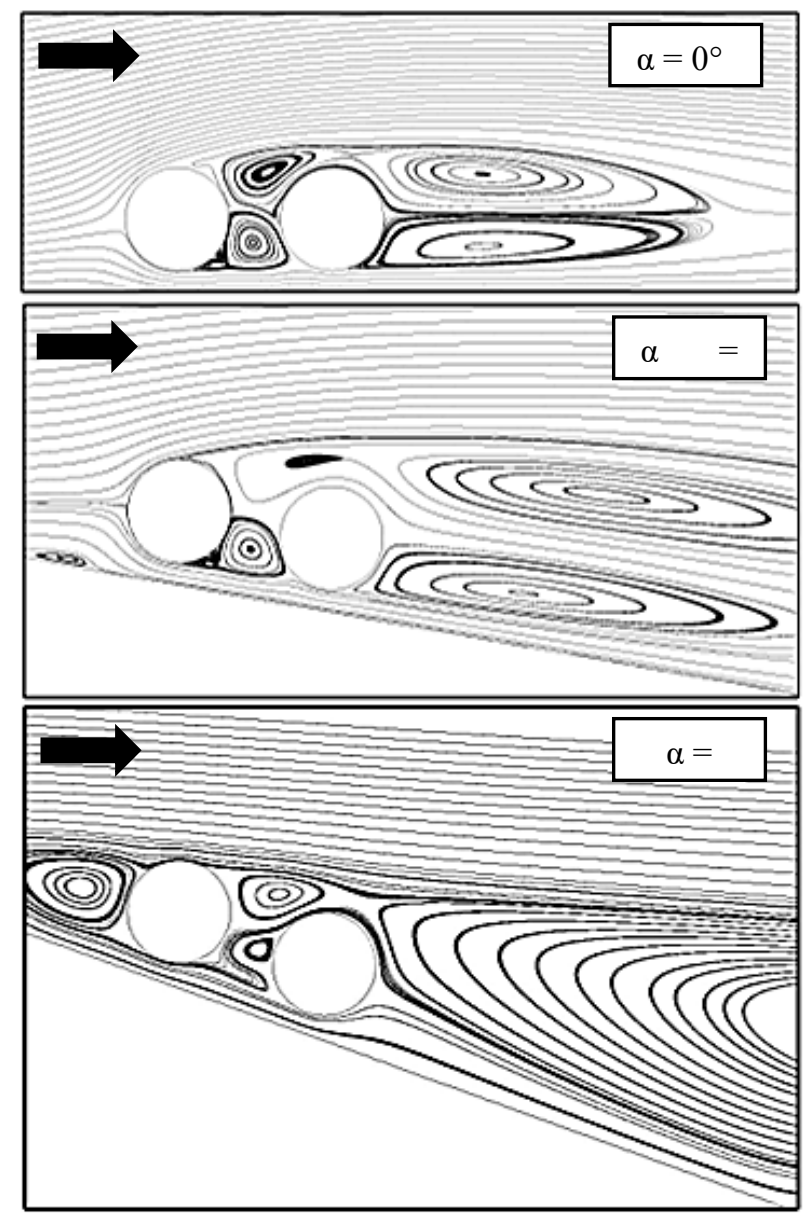

Gambar. 12. Streamline pada setiap variasi $\alpha$ pada $\mathrm{G} / \mathrm{D}=0,2$

\section{KESIMPULAN/RINGKASAN}

Peningkatan G/D akan mengurangi efek blockage pada sisi depan silinder-1. Blockage yang berkurang menyebabkan laju massa aliran di sisi celah bertambah sehingga akselerasi aliran akan semakin tinggi di sisi bawah kedua silinder. Peningkatan inclined wall angle $(\alpha)$ akan membentuk recirculation zone akibat wake step dari kemiringan dinding.

Pada $\alpha=0^{\circ}$, Peningkatan G/D akan menurunkan CDp dan CLp pada silinder-1. CDp turun (dan bernilai negatif) dan CLp naik pada silinder-2. 
Pada $\alpha=10^{\circ}$, Peningkatan G/D akan meningkatkan CDp, CLp relatif naik turun (dan bernilai negatif) pada silinder-1. Sedangkan CDp turun (dan bernilai negatif) serta CLp naik pada silinder-2.

Pada $\alpha=20^{\circ}$, Peningkatan G/D akan meningkatkan CDp dan menurunkan CLp (konstan menurun pada $\mathrm{G} / \mathrm{D} \leq 0,4$ ) pada silinder-1. Sedangkan CDp konstan pada G/D 0,1-0,4 dan menurun pada $\mathrm{G} / \mathrm{D} \geq 0,5$, CLp naik (konstan naik pada $\mathrm{G} / \mathrm{D} \leq 0,4)$ pada silinder-2.

Peningkatan $\alpha$ pada setiap variasi G/D akan menurunkan nilai CDp dan CLp secara konsisten pada silinder-1 dan meningkatkan CDp namun tetap bernilai negatif serta menurunkan nilai CLp pada silinder-2.

\section{DAFTAR PUSTAKA}

[1] P. W. Bearman and M. M. Zdravkovich, "Flow around a circular cylinder near a plane boundary,” J. Fluid Mech., vol. 89, no. 1, pp. 33-47, Nov. 1978.
[2] W. A. Widodo, "Pemodelan numerik aliran melintasi dua silinder sirkulasi tersusun tandem dengan pengaruh side wall dengan jarak gap (G/D =0.2), ” in Prosiding Seminar Nasional Perkembangan Riset dan Teknologi di Bidang Industri ke 16, 2010.

[3] T. Yuwono, F. Fahreza, and W. A. Widodo, "Flow around two circular cylinders in tandem arrangement near a plane wall,” in Regional Conference on Mechanical and Aerospace Technology, 2010.

[4] P. Louda, J. Př́hoda, K. Kozel, and P. Sváček, "Numerical simulation of flows over 2D and 3D backward-facing inclined steps," Int. J. Heat Fluid Flow, vol. 43, pp. 268-276, Oct. 2013.

[5] B. Ruck and B. Makiola, "Flow Separation over the Inclined Step," in Physics of Separated Flows - Numerical, Experimental, and Theoretical Aspects, K. Gersten, Ed. Wiesbaden: Springer, 1993, pp. 47-55.

[6] H. K. Versteeg and W. Malalasekera, "An introduction to computional Fluid Dynamics,” England, 2007.

[7] F. P. Incropera, D. P. Dewitt, T. L., A. Bergman, and S. Lavine, Fundamentals of Heat and Mass Transfer, 7th ed. New York: John Wiley \& Sons Inc, 2011.

[8] R. W. Fox, P. J. Pritchard, and A. T. McDonald, Fox and McDonald's introduction to fluid mechanics., 8th ed./. Hoboken NJ: John Wiley \& Sons, Inc., 2011 